\title{
Digital technologies in supply chain management
}

\author{
Arenkov Igor \\ Economic Faculty \\ St. Petersburg University \\ St. Petersburg, Russia \\ email address: igararenkov@gmail.com
}

\author{
Tsenzharik Maria \\ Economic Faculty \\ St. Petersburg University \\ St. Petersburg, Russia \\ email address: matiac@yandex.ru
}

\author{
Vetrova Maria \\ Economic Faculty \\ St. Petersburg University \\ St. Petersburg, Russia \\ email address: mvetrova@ocs.ru
}

\begin{abstract}
With the rise of Industry 4.0, novel technologies open new opportunities for business transformation. These technologies change supply chains and drive new ways to create value. However, not all companies chose this path of digitalization due to significant investment costs, and thus risk becoming laggards. This article analyses three key areas of digital technologies development and their impact on the transformation of supply chains, including the emergence of closed loop chains as the basis for a circular economy. This paper provides practical examples of supply chain digitalization, as well as its socio-economic and environmental effects. It will be shown that the formation of a common information space for all participants and the transformation of the supply chain into an ecosystem has the greatest influence on supply chains.
\end{abstract}

Keywords - digital technologies; digital transformation; digital economy; digital supply chain; circular economy; closed loop supply chain; digital ecosystem

\section{INTRODUCTION: CONTRIBUTION OF THE DIGITAL TECHNOLOGIES}

It is impossible to deny that digital technologies have fundamentally changed consumer behaviour, company activities and the relationships between all elements of the economy. Thus, mobile Internet has led to the "always online" mentality and the hyper-connectedness of people, companies and machines in the digital economy. Social networks accumulate a great volume of information on all of their users. Artificial intelligence provides algorithmic decision-making and automated processes management. BigData technology allows large quantities of structured and unstructured data and predictive analytics to be processed. Cloud technologies transfer complex data and knowledge to all ecosystem members. In many processes smart robots make human participation almost redundant. The augmented reality provides the opportunity to see business processes in a holistic and detailed manner. The Internet of Things makes it possible to remotely manage processes and systems, while blockchain ensures the verification of participants and transactions reliability.

Interestingly, digital technologies have both affected operations and accelerated the development and implementation of non-digital innovations, such as nanotechnologies, cognitive technologies, autonomous automobiles, genetic engineering, energy storage, 3Dprinting, new manufacturing materials, new ways of oil and gas exploration and extraction and renewable energies.
For example, the amount of energy generated by solar and wind sources depends on the weather conditions and may fluctuate at times, causing energy surpluses or deficits. Smart grids provide interaction between producers, electric power consumers and network regulatory systems. Like the Internet, a smart grid comprises controllers, computers, automatic processes and digital technologies working in unison with manufacturing equipment. The major function of a smart grid is to provide as digital response to the rapidly changing demand for electricity and aligning it with the supply.

Despite having great potential, digital technologies are not applied in all companies to the same extent and have different levels of effectiveness due to varying levels of development and alignment. This is demonstrated in the hype cycle, which is developed by Gartner annually. Thus, in 2019, the main trends and driving forces behind the changes in operations and business models are presented by blockchain, quantum computing, augmented analytics and artificial intelligence [1].

At the same time, at a company level, the following dynamics are observed. According to a survey of 4,600 business leaders from 42 countries, which was conducted by Dell company, there are five distinct areas in which companies invest in digital transformation: cybersecurity, Internet of Things, multi-cloud environment, artificial intelligence, compute centric approach [2].

Our study is focused, first, on the analysis and classification of digital technologies application, focusing on their impact on supply chains transformation; second, on identifying the central factors of supply chains digitalization, with the use of case studies of closed loop supply chains; third, on identifying the dominating trends in supply chains development and their transformation into ecosystems which coordinate the actions of all their participants and elements.

\section{SUPPLY CHAIN DIGITALIZATION}

The business models of some companies (e.g. Google, Amazon, Alibaba, Airbnb, Uber) are fundamentally built on digital technologies. Other companies, whether they have existed for five, ten, twenty or even one hundred years, are forced to transform and embrace digital technologies in order to compete. This process has various names such as digitization, digitalization or digital transformation. We will now define these terms in detail.

Digitization is the process of creating digital versions of analogue/physical things such as paper documents, microfilm 
images, photographs, sounds, and more. Thus, it is simply converting something non-digital (other examples include signals, health records, location data, identity cards, etc.) into a digital format which can then be used by a computing system for numerous possible purposes [3]

As a result, we are getting continuous information flows in a digital form, leading to the acceleration and improvement of operations accuracy and a reduction in the staff required. The digitization creates the ground for operations automation and digitalization.

Digitalization means adding digitality to interactions, communications, business functions and business models, which often leads to a mix of digital and physical, such as in omni-channel customer service, integrated marketing or smart manufacturing with a mix of autonomous, semi-autonomous and manual operations [3].

Thus, digitalization is the improvement of functions and business processes with digital technologies and digital data. The basis for digital processes is the use of detailed analytics for the managing of company operations. We can talk about the digitalization of production or the digitalization of marketing, which means that many functions and operations will be carried out automatically without human participation. Digitalization lays the groundwork for transition to digital business.

Digital transformation is a transition to digital business: a complex transformation of business activities, processes, models and employees' competences to fully exploit digital opportunities. Very often, digital transformation leads to the emergence of new markets, new consumers, and a new business. A detailed study of the digital transformation stages is presented in [3].

Generally speaking, digitalization and digital transformation are aimed at achieving the following objectives:

- Use of information in the digital form

- $\quad$ Sensory interaction with devices

- Managing customer experience

- $\quad$ Providing cybersecurity

- Automation of operations and decision-making

- Usage of external and internal social networks

A Digital Supply Chain (DSC) is a smart, value-driven, efficient process to generate new forms of revenue and business value for organizations and leverage new approaches with novel technological and analytical methods. DSC is not about whether goods and services are digital or physical; it is about how supply chain processes are managed with a wide variety of innovative technologies, e.g. unmanned aerial vehicles, cloud computing, and Internet of Things, among others [4].

We can also find a definition of Supply Chain 4.0 as the application of Internet of Things, the use of advanced robotics, and the application of the advanced analytics of Big Data in supply chain management: place sensors in everything, create networks everywhere, automate anything, and analyze everything to significantly improve performance and customer satisfaction [5].

The use of digital technologies leads to positive economic effects, such as the economy of raw materials and energy resources, due to production and consumption rationalization, as well as to the perspective of environmental rehabilitation and restoration. All this contributes to the formation of a new model of economy that is called the circular economy. This is an economy based on reconstruction, optimization and resource saving processes, facilitated by digital technologies, which achieves non-waste production and consumption, sustainable economic growth and socio-economic and environmental efficiency. The key concept of the circular economy is the development of closed loop and sustainable supply chains.

Sustainable, or green, supply chains mean that the principles of sustainable environmental and economic growth are implemented into a traditional supply chain. The selection of suppliers, product design, manufacturing, assembly, distribution, sustainable use, consumption and disposal are subject to these requirements. Thus, the circular economy and closed loop supply chains bring companies to a new level of innovation and competitiveness, generate new revenue sources, and enable the creation of value across the entire supply chain.

In a circular economy, supply chain digitalization is aimed at providing the necessary information on important elements and business processes, on bottlenecks and interruptions, as well as on options for optimizing key indicators for effective resource usage and cost reduction to achieve social, economic and environmental objectives. Digital technologies help create innovative supply chains, taking into account the product life cycle, its impact on the environment, not only in the production process, but also in use, while optimizing costs and minimizing the negative effects of production and consumption.

\section{DIGTAL TECHNOLOGIES IN SUPPLY CHAIN MANAGEMENT}

In supply chain optimization, a wide range of instruments of varying complexity and costs are employed, for instance, software products for efficient supply chain design, providing systemic integration, such as SAP, Oracle etc. Supply chain management traditionally applies scenario and simulation modelling, operations research, production and inventory control.

It is clear that the greatest efficiency is achieved through the joint application of digital and information systems. For example, electronic procurement and automated vendor search are instruments that use digital technologies and Internet applications in combination with ERP systems, which allow the automation of both internal and global business processes. Procurement specialists worldwide can easily share information to simplify the process and to save time and money without a negative impact on product quality and standards.

The variety of technologies can be grouped into three large areas: data analytics and visualization technologies; technologies for operations automation and equipment management; technologies providing communications between supply chain participants (see Table 1). 
We will now consider how technologies are used in closed loop supply chains, focusing both on direct and reverse material, components and goods flows. These processes, including the activities related to the product or its post-sale maintenance, with the aim of optimizing, improving service efficiency, reducing costs and saving environmental resources, are known as reverse logistics[10].

TABLE 1. DigITAL TECHNOLOGIES IN SCM, COMPILED BY THE AUTHORS USING $[6,7,8,9]$

\begin{tabular}{|c|c|c|c|}
\hline $\begin{array}{c}\text { Goa } \\
\text { l }\end{array}$ & Functions & $\begin{array}{l}\text { Information } \\
\text { and } \\
\text { automation } \\
\text { systems and } \\
\text { technologies }\end{array}$ & $\begin{array}{c}\text { Digital } \\
\text { technologies }\end{array}$ \\
\hline 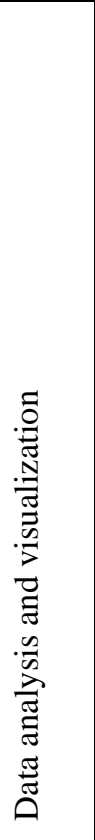 & $\begin{array}{l}\text { Navigation of } \\
\text { business } \\
\text { processes, } \\
\text { electronic } \\
\text { catalogues data } \\
\text { unification, } \\
\text { integration of } \\
\text { information } \\
\text { systems, } \\
\text { monitoring } \\
\text { supply chain, } \\
\text { real time } \\
\text { planning of } \\
\text { enterprise } \\
\text { activity, } \\
\text { administration of } \\
\text { product data and } \\
\text { events, data } \\
\text { processing, } \\
\text { predictive } \\
\text { analytics }\end{array}$ & $\begin{array}{l}\text { SCOR, ISO } \\
\text { и CALS- } \\
\text { standards, } \\
\text { ERP, PIM, } \\
\text { SCEM, } \\
\text { TMS, } \\
\text { SCMo, } \\
\text { Real-time } \\
\text { Factory } \\
\text { Scheduling }\end{array}$ & $\begin{array}{l}\text { Big Data, } \\
\text { artificial } \\
\text { intelligence, } \\
\text { cloud } \\
\text { computing } \\
\text { and storage, } \\
\text { quantum } \\
\text { computing, } \\
\text { S\&OP } \\
\text { platforms, } \\
\text { smart } \\
\text { warehouse, } \\
\text { wearables }\end{array}$ \\
\hline 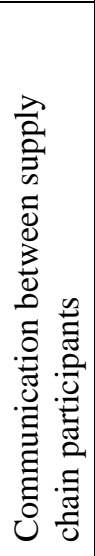 & $\begin{array}{l}\text { Automated } \\
\text { supplier search, } \\
\text { electronic } \\
\text { procurement, e } \\
\text { - commerce, } \\
\text { supply chain } \\
\text { processes } \\
\text { synchronization } \\
\text {, supply chain } \\
\text { transparency, } \\
\text { communication } \\
\text { between supply } \\
\text { chain elements }\end{array}$ & $\begin{array}{l}\text { CRM, SRM, } \\
\text { CSRP, } \\
\text { AMS, Single } \\
\text { Window, } \\
\text { EDI, EANC } \\
\text { OM, } \\
\text { EDIFACT, } \\
\text { digital } \\
\text { signiture }\end{array}$ & $\begin{array}{l}\text { Automated e- } \\
\text { sourcing, } \\
\text { omni-channel } \\
\text { Smart } \\
\text { Fulfillment } \\
\text { Solution, } \\
\text { blockchain, } \\
\text { social media } \\
\text { marketing, } \\
\text { feedback } \\
\text { loop, social } \\
\text { networks, } \\
\text { industrial } \\
\text { cloud }\end{array}$ \\
\hline
\end{tabular}

\begin{tabular}{|c|c|c|c|}
\hline 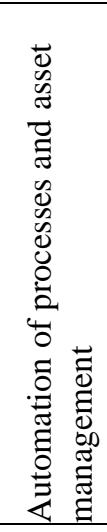 & $\begin{array}{l}\text { Flexible } \\
\text { automation of } \\
\text { production, } \\
\text { digital } \\
\text { production } \\
\text { processes, digital } \\
\text { product quality, } \\
\text { digital reverse } \\
\text { engineering, } \\
\text { virtual analogues } \\
\text { for physical } \\
\text { products/product } \\
\text { ion }\end{array}$ & $\begin{array}{l}\text { Robots, } \\
\text { automatic } \\
\text { production } \\
\text { lines, WMS, } \\
\text { Flexible } \\
\text { Factory } \\
\text { automation, } \\
\text { RFID }\end{array}$ & $\begin{array}{l}\text { Digital twins, } \\
\text { 3D-seal, } \\
\text { sensors, } \\
\text { driverless } \\
\text { vehicles } \\
\text { mixed and } \\
\text { augmented } \\
\text { reality, } \\
\text { industrial } \\
\text { IoT, additive } \\
\text { manufacturin } \\
\text { g, intelligent } \\
\text { robots } \\
\end{array}$ \\
\hline
\end{tabular}

The key objective is to efficiently generate, collect, store and analyse information on each product design and composition, specifics of use, location, disassembly capabilities, various ways of recycling, etc. All this is necessary to create multiple product lifecycles in the later stages after initial use. Previously, the lack of up-to-date information in all parts of the chain did not allow effective closed loop supply chains, but now the spread of digital technologies ensures the development of the closed product life cycle.

Thus, cyberphysical systems allow access to information on products in all stages of production and use, impact on the environment of all processes and product handling. This reduces the information asymmetry as producers reveal information on products' components and materials while consumers' use of the product is also monitored. Sensors track down, in real time, the exact location of the product at the end of its use. Big Data analytics is transferred to companies utilizing used products as core production resources. The optimization of primary resources' demand and supply according to waste and recyclables amounts is revolutionized with digital platforms, which form the markets for used products, with application of IoT sensors. These sensors provide data on the products' composition and indicate possibilities for their further application. As a result, recycled resources are getting cheaper and more price competitive than primary resources and materials. Thus, digital markets for recycling products and waste are emerging.

Key processes, consolidating products, components, materials and resources within the supply chain, enable the extension of the product life cycle, by reusing, repairing and refurbishing a used product to achieve the quality of a new product, or save resources, through processing and extrusion of new materials, energy and fertilizers.

It should be noted that digital technologies have varying degrees of relevance for individual processes generating reverse flows. Figure 1 represents the product life cycle in phases: from extraction of raw materials and energy resources necessary for production, to its disposal at end of use. Each process in the reverse flow returns a product to a certain life cycle stage, e.g. reprocessing returns the material flow to Stage 2 - Manufacturing of details and components. Here, the processes of energy generation by burning waste and its disposal do not participate in the closed loop supply chains, as they are not intended to conserve resources inside the supply chain and so should be minimized. 


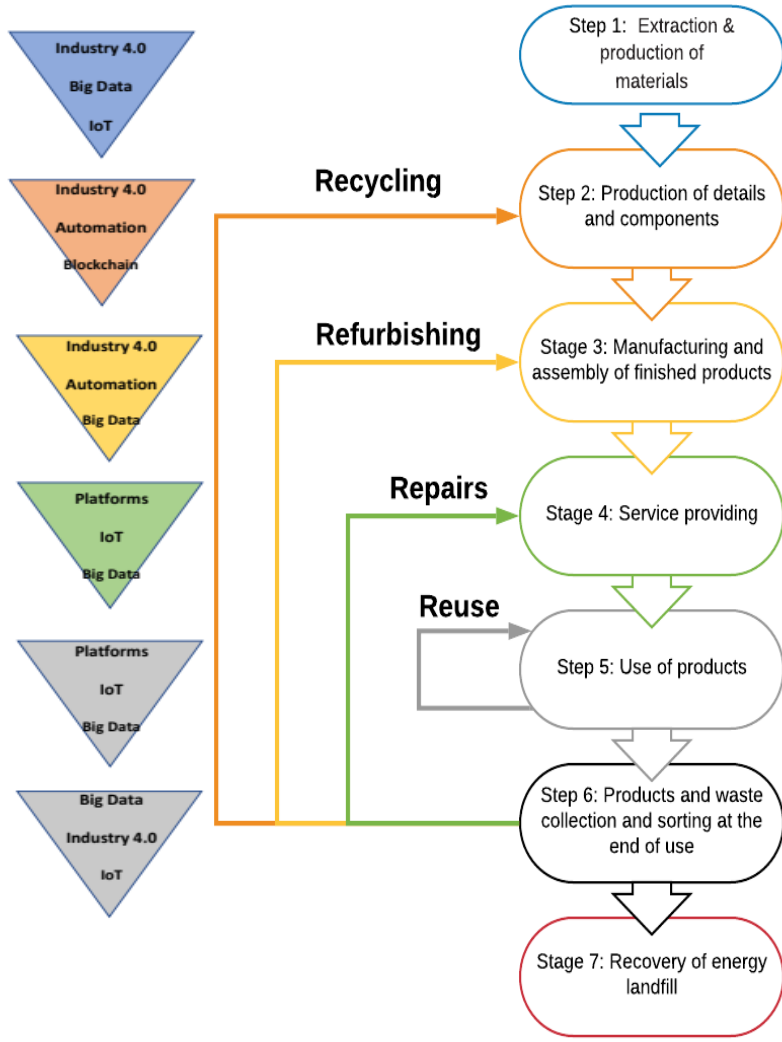

Fig. 1. Digital technologies supporting reverse material flows in a closed loop supply chain. Compiled by the authors based on $[11,12,13,14,15,16]$

Stage 1. Consumption and use of primary materials is minimized by Industry 4.0 technologies, with the flagship being 3D-printing, which not only allows the personalization of products and the reduction of consumption but also the recycling of $3 \mathrm{D}$ waste and conversion back into usable filament.

Stage 2. Manufacturing of elements and components includes the selection of materials that are most suitable for future recycling, including biodegradables. Also, any ecodesign product should have a long life cycle and, where applicable, the possibility to repair or refurbish it. Big Data and high-performance computing, vendor search automation and digital twins provide a vast range of opportunities to advance eco-design.

Stage 3. Products are designed to allow future automated disassembly with minimal manual labour. Particular attention is paid to the labelling and certification of individual items for future recycling. Thus, Michelin fit IoT sensors directly into their tyres to allow real time monitoring of tyres. When critical wear levels are reached, vehicles are recalled to the factory for restoration of tyres, with the reconstruction costs being around half the cost of raw materials required to manufacture a new product [17].

Stage 4. Offering services and goods for temporary use is actively developing as an alternative to goods ownership. Mass customization prevails over mass standardization, and the permanent improvement of products for customer requirements is implemented through feedback loops and predictive analytics systems. For example, Hello Tractor company from Nigeria uses mobile technology to provide
250,000 small farmers with access to tractors at a convenient time, improving their food security and optimizing costs. Instead of buying and maintaining the tractor, a farmer rents it. In addition, tractors are equipped with M2M technology to share information about the vehicle and its efficiency, which in turn maximizes its use and extends the life of the tractor [18].

Stage 5. In the process of use, products are controlled by manufacturers, and when exhausted, or broken, or obsolete, they are effectively disposed of in the most eco-friendly way. The use of automation technologies and predictive analytics is extremely relevant at this stage. Thus, a robot for the disassembly of the Apple iPhone has 29 hands and is able to decompound a used iPhone in 11 seconds and divide its components into useful materials. To date, Apple has extracted 61 million pounds of materials that can be used in future products, including 2,204 pounds of gold, worth 40 million dollars [19].

Stage 6. The collecting and sorting of waste and used products is highly effective with IoT, feedback platforms and Big Data. Location, quality and product ownership monitoring as well as defining actors responsible for disposal are extremely important. For instance, in the U.S. the cloud-based Big Data analytics platform Rubicon connects waste producers with a network of independent waste carriers in 50 U.S. and Canadian states, as well as in 18 other countries. This provides higher recycling rates, a tailored approach to waste reuse, optimized transport routes and detailed analysis of waste data.

The global digitalization trend has led to an emergence of closed loop supply chains and the development of a fundamentally new model of circular economy based on the 'take-make-reuse' principle [20]. Today, the circular economy is the ground for achieving the sustainable development goals of SDG9 (sustainable industrialization) and SDG12 (sustainable production and consumption). Thus, the digital circular economy is characterized by non-waste production and consumption, minimal materials used per produced unit and transforming commercial and personal waste into a useful resource for further utilization.

\section{SUPPLY CHAIN AS AN ECOSYSTEM}

As we can see, supply chain management conception is a continuous coordination of participants' actions in order to organize logistic processes and reduce the cost, time and risks associated with material movement across the entire supply chain. In the pre-digitalization era, the coordination of participants was carried out by a central company and was based on use of information systems (ERP, CRM, SRM, WMS etc). The most challenging obstacles for smooth interaction between supply chain elements were:

- different, often incompatible information systems of parties

- disconnected communication and marketing channels (telephone, mail, fax, e-mail, electronic documents, personal contacts)

- lack of regular information exchange not just between separate entities but also between various departments within the same company. 
Digital technologies offer efficient solutions to these issues through creating a common digital space for various supply chain participants. Among them, clients and suppliers, transport and logistic companies, wholesalers, retailers, distributors, warehouses, as well as financial and consulting firms. The continuous access of participants to actual information determines all characteristics of a supply chain.

Since the last century, various attempts to build a common information space have been made. To this end, one of the first common information spaces, Single Window, was created by companies operating in the port of Felixstow (UK) in 1984. The prevalent cause of the port's inefficiency was paper document flows: the customs processing time for arriving ships in the port exceeded five days. The port stakeholders (shipping lines and agents, forwarders and brokers, customs and government authorities) invested in the development of the port community system with the electronic document flows between supply chain participants for arriving ship cargo. As the result, the time spent on the port cargo handling was reduced to six hours and the transparency and efficiency of the logistic processes was improved, which attracted new investments to the transport industry. Later, the Single Window system was implemented at many other major border checkpoints (ports and airports), and electronic document (EDI and EDIFACT) standards were registered under ISO [21].

Later, such systems attracted interest from international organizations, especially those operating in the field of customs and border control. In 2008, the EU Single Window Environment for Customs program was launched, thus creating a legal framework for replacing paperwork with electronic communications at border checkpoints - an initiative which still remains an important element of international trade [22]. In Russia, Single Window system for the Federal Customs Service have also been implemented, and by 2016 over $99 \%$ of customs declarations for imported and exported goods were submitted electronically. The country's Public Services portal is also based on the Single Window approach.

Thus, evolving ecosystems are an important trend in supply chain management. The popular concept of the ecosystem was taken from biology and applied to economics and management by J. F. Moore in 1993. He defined a business ecosystem as a flexible structure consisting of people and firms interacting with each other to create and share values within the system [23]

An ecosystem, tapping into the participants' potential, drives new opportunities for creating new products, services and increasing customer satisfaction. An ecosystem can include supply chain participants, partner companies, consumers and even competitors. In the digital economy, the ecosystems are based on digital technologies and comprise not just companies and people but also objects and devices and thus are called digital ecosystems. Usually, ecosystems are underpinned by digital platforms.

Many prominent manufacturing companies create ecosystems of supply chain participants. For example, Bosch has set out to create a connected logistics system and to link all electronic components through the Internet of Things [24]. To ensure a rapid response to change, it was decided to create a flexible ecosystem for the company and suppliers. The company led a consortium of German manufacturers to develop standards for automated production and Industry 4.0. As the next step, the company intends to connect its smart factories through the Internet, which will allow them to autonomously adjust to equipment downtime and to fluctuations in the material supply and demand. Thus, in the digital ecosystem, a dynamic supply chain from the supplier of raw materials to the end consumer is formed.

Volkswagen company, in collaboration with Amazon Web Services, is creating a digital ecosystem that will combine real time data from 122 plants, machines and systems to optimize internal systems and processes [25]. The next step is to create the Volkswagen Industrial cloud and integrate 30,000 delivery locations owned by the company's 1,500 suppliers and partners into a unified system. This will make it possible to identify any bottlenecks and optimise the supply chain. The core concept for the new Volkswagen Industrial cloud is an open industry platform which the company's production, logistics and trading partners may use in the future. This digital ecosystem is based on cloud technology, IT-security, advanced analytics and the industrial Internet of Things.

Supply chains are thus being transformed into ecosystems coordinated by a central platform that is continuously accumulating and processing data on the interactions of people, processes and devices in the ecosystem. They, in turn, form a new logic for the material flows movement in an ecosystem. Coordination within a supply chain is becoming more flexible and dynamic, thus transcending boundaries between individual businesses and leading to the notion of an 'extended firm' and a dynamic supply chain.

A platform hosting an ecosystem is able to accumulate data not only on material flows and inventories but also on the suppliers' reputation assessed through in-depth analysis of their activities. Such information is used to support both tactical and strategic cooperation and contracting decisions.

Supply chains are evolving into platform based digital ecosystems, which leads to the emergence of network effects as improved coordination between the ecosystem members and better reputation management attract even better and more reliable suppliers, resulting in a more sustainable ecosystem [26].

Until recently, supply chains have been largely systems where participants are closely linked by contractual relations. However, as supply chains undergo digital transformation, we are going to witness more flexible processes, new business models and supply ecosystems facilitated by network effects.

\section{CONCLUSION}

According to some forecasts, about $50 \%$ of the largest companies on the Fortune Global 500 list are going to be superseded by innovative digital enterprises within the next ten years [27]. This means that digital technologies have huge potential for changing consumer expectations, operations and communications processes, supply chains forms and characteristics and, finally, for transforming any economic systems. The changes will occur through a wider and more profound automation of processes, use of more sophisticated advanced analytics and shift from linear supply chains to digital platforms and supply ecosystems. 


\section{REFERENCES}

[1] Gartner Top 10 Strategic Technology Trends for 2019 URL: https://www.gartner.com/smarterwithgartner/gartner-top-10-strategictechnology-trends-for-2019/ (reference date: 29.06.2019)

[2] Top 5 technology investments that will drive digital transformation URL: https://www.techrepublic.com/article/top-5-technologyinvestments-that-will-drive-digital-transformation/ (reference date: 29.06.2019)

[3] Digitization, digitalization and digital transformation: the differences URL: https://www.i-scoop.eu/digitization-digitalization-digitaltransformation-disruption/ (reference date: 29.06.2019)

[4] Digital Supply Chain: Literature review and a proposed framework for future research URL:

https://www.sciencedirect.com/science/journal/01663615 (reference date: 29.06 .2019 )

[5] Supply Chain 4.0 - the next-generation digital supply chain, 2016 URL: https://www.mckinsey.com/business-functions/operations/ourinsights/supply-chain-40--the-next-generation-digital-supply-chain (reference date: 29.06.2019)

[6] Pagoropoulos, A., Pigosso, D. C. A., \& McAloone, T. C. (2017). The emergent role of digital technologies in the Circular Economy: A review. Procedia CIRP, 64, 19 - 24 https://doi.org/10.1016/j.procir.2017.02.047

[7] Bressanelli G, Adrodegari F, Perona M, Saccani N. Exploring How Usage Focused Business Models Enable Circular Economy through Digital Technologies. Sustainability 2018; 10:639. doi:10.3390/su10030639

[8] Salminen V, Ruohomaa H, Kantola J. Digitalization and big data supporting responsible business co-evolution. Adv. Intell. Syst. Comput., vol. 498, Springer, Cham; 2017, p. 1055-67. doi:10.1007/978-3-319-42070-7_96.

[9] Bressanelli G, Adrodegari F, Perona M, Saccani N. The role of digital technologies to overcome Circular Economy challenges in PSS Business Models: an exploratory case study / Procedia CIRP 73 (2018) 216-221

[10] Gailen V. What is Reverse Logistics? / Gailen Vick // URL: http://www.reverselogisticstrends.com/reverselogistics.php (reference date: 29.06.2019)

[11] Circular economy, your digital path. How digital enables the transformation into the sustainable circular economy/ White paper Scientifc Community. Thought Leadership Atos URL: https://atos.net/wp-content/uploads/2019/02/atos-circular-economywhite-paper.pdf (reference date: 29.06.2019)

[12] Ghisellini P, Cialani C, Ulgiati S. A review on circular economy: the expected transition to a balanced interplay of environmental and economic systems. J Clean Prod 2016; 114:11-32. doi:10.1016/j.jclepro.2015.09.007.

[13] Ardolino M, Rapaccini M, Saccani N, Gaiardelli P, Crespi G, Ruggeri C. The role of digital technologies for the service transformation of industrial companies. Int J Prod Res 2017; 7543:1-17. doi:10.1080/00207543.2017.1324224.
[14] R.Pardo, J.P Schweitzer (2018): 'A long-term strategy for a European circular economy - setting the course for success', Policy Paper produced for the Think2030 project, Brussels, November 2018

[15] Neligan A. Digitalization as Enabler Towards a Sustainable Circular Economy in Germany/ Inter-economics 2018, p. 101-106 doi: 10.1007/s10272-018-0729-4

[16] Ellen MacArthur Foundation. Towards the circular economy; Ellen MacArthur Foundation: UK, 2013.

[17] Reinventing the wheel: Why smart tyres give the IoT real grip URL: https://internetofbusiness.com/reinventing-the-wheel-smart-tyres-andthe-iot/(reference date: 29.06.2019)

[18] Hello tractor URL: https://www.hellotractor.com/about-us/ (reference date: 29.06 .2019$)$

[19] Apple unveils 29-armed robot designed to disassemble old iPhones URL: https://www.extremetech.com/mobile/225337-apple-unveils29-armed-robot-designed-to-disassemble-old-iphones (reference date: 29.06.2019)

[20] Ellen MacArthur Foundation. Intelligent Assets: Unlocking the Circular Economy Potential. Ellen MacArthur Found, 2016.

[21] Alan Long. Port Community systems. World customs journal, Vol.3 N1, 2009 URL: https://pdfs.semanticscholar.org/93a7/e67f0520ca23f71eb73f2dfb937 24f191724.pdf (reference date: 29.06.2019)

[22] The EU Single Window environment for customs URL: https://ec.europa.eu/taxation_customs/general-informationcustoms/electronic-customs/eu-single-window-environment-forcustoms_en_(reference date: 29.06.2019)

[23] J.F.Moore. Predators and Prey. Harvard Business Review, 1993 MayJun; 71(3): 75-86.

[24] Volkswagen and Amazon Web Services to develop Industrial Cloud URL: https://www.volkswagen-newsroom.com/en/pressreleases/volkswagen-and-amazon-web-services-to-develop-industrialcloud-4780 (reference date: 29.06.2019)

[25] Always on board you're your freight is on the move. Bosch connected logistics. URL:

https://www.boschservicesolutions.com/monitoring/connectedlogistics/ (reference date: 14.07.2019)

[26] The future of supply chains as neteworked ecosystems. https://platformed.info/the-future-of-supply-chains-as-networkedecosystems/ (reference date: 14.07.2019)

[27] Anthony S/, Viguerie P., Waldeck A. Corporate Longevity: Turbulence Ahead for Large Organizations/ Innosight executive briefing URL: https://www.innosight.com/wpcontent/uploads/2016/08/Corporate-Longevity-2016-Final.pdf (reference date: 29.06 .2019 ) 